\title{
Avaliação de Metodologias de Determinação do Cálculo de Áreas de Contribuição
}

\author{
Verônica Moreira Ramos,'Renato Fontes Guimarães, André Luciancencov Redivo, ${ }^{1}$ \\ Osmar Abílio de Carvalho Júnior, Nelson Ferreira Fernandesẻ \\ Roberto Arnaldo Trancoso Gomes ${ }^{3}$ \\ ${ }^{1}$ Departamento de Geografia - Universidade de Brasília (UnB) \\ $\{$ vmramos, renatofg\}@unb.br \\ ${ }^{2}$ Instituto Nacional de Pesquisas Espaciais (INPE) \\ osmar@1tid.inpe.br \\ ${ }^{3}$ Departamento de Geografia Universidade Federal do Rio de Janeiro (UFRJ) \\ nelsonff@acd.ufrj.br
}

\begin{abstract}
Resumo
A área de contribuição ou área drenada à montante de cada célula de uma matrizestá relacionada ao valor da área correspondente à bacia de cada célula específica. Portanto, para a determinação do mapa de área de contribuição calcula-se o valor da bacia de drenagem de cada célula que compõe a área que será mapeada. Tendo como objetivo a obtenção de um mapa de área de contribuição o mais confiável possível, determinou-se esse parâmetro a partir de duas metodologias distintas. A primeira, TU Transferência de fluxo para uma única célula, determina a área de contribuição em função da célula que apresentam maior valor de declividade. A Segunda, TD - Transferência de fluxo distribuída, calcula a área de contribuição distribuindo o fluxo proporcionalmente entre as células localizadas à jusante, de acordo com a declividade local. A metodologia de transferência de fluxo distribuída (TD) mostrou-se mais eficiente, pois sugeriu com exatidão a rede de drenagem, localizando as maiores áreas de contribuição de montante para jusante exatamente na calha, não só da drenagem, mas de todos os caminhos preferenciais de fluxo.
\end{abstract}

Palavras Chave: área de contribuição, declividade, Modelo Digital de Terreno.

\begin{abstract}
The contribution area or upward drained area of each grid cell is related to the value of the corresponding area to the basin of each specific pixel. Therefore, for the determination of the contribution area map it is calculated the value of the drainage basin of each pixel that comprises the area that will be mapped. In order to obtain the most reliable contribution area map, this parameter was determined from two distinct methodologies. The first determines the calculation of contribution area based on the cell that has the largest gradient value (this methodology is used by Arcinfo, ArcView software, among others). The second uses an algorithm, which in this work was written in $\mathrm{C}$ language, which makes the calculation of contribution area distributing proportionally the flow among located cells for downslope, according to the local gradient. The methodology that determines the contribution area for one given cell distributing the flow proportionally between those located to downward showed more efficient, because it suggested with accuracy the drainage network, locating the biggest contribution areas from upward to downward exactly in the gutter, not only of the drainage, but also of all the preferential flow ways.
\end{abstract}

Keywords: contribution area, slope, Digital Elevation Model. 


\section{Introdução}

Os modelos hidrológicos são usados para determinar o balanço de água no solo, procurando simular o percurso da água desde a precipitação até o escoamento ou a evapotranspiração. Isto é, esses modelos descrevem matematicamente a distribuição espacial da precipitação, as perdas por evapotranspiração, o movimento da água no solo causado pela infiltração, percolação e o escoamento, tanto superficial quanto subsuperficial, bem como nos canais de escoamento.

Beven e Kirkby (1979), por exemplo, objetivando a determinação de zonas de saturação no solo, desenvolveram um modelo hidrológico baseado em dados físicos que é amplamente utilizado na previsão de escoamento. Esse modelo baseia-se na teoria de contribuição variável para a formação do escoamento, estimando a deficiência de água no solo e a área de contribuição a montante, ou área fonte saturada, a partir de características topográficas e do solo. Eles mostraram que o padrão de saturação está diretamente relacionado com a razão $(a / b) / M$, onde a é $\mathrm{a}$ área drenada, b é o comprimento de contorno e $\mathrm{M}$ é a declividade.

O'Loughlin (1986), com base nesse princípio, desenvolveu um modelo hidrológico que mapeia o padrão espacial de saturação do solo a partir da análise da área de contribuição a montante, da transmissividade do solo e da declividade local, considerando que a direção do fluxo subsuperficial é determinada pela topografia local. Mais recentemente Dietrich et al (1993), aprimoraram esse modelo utilizando-o como base para estudos de previsão de áreas de instabilidade na paisagem, mais precisamente para prever zonas de saturação em áreas que apresentam intensos processos erosivos.

A determinação da área de contribuição é de extrema importância nos estudos de previsão e definição de áreas de instabilidade, sobretudo nas porções côncavas do relevo (hollows), uma vez que essas são zonas potenciais de saturação e, desta forma, de instabilidade. Inúmeros cientistas mostraram, a partir de modelos hidrológicos, a importância do parâmetro topográfico, área de contribuição na predição e definição de áreas de instabilidade (Beven e Kirkby, 1979; Montgomery e Dietrich, 1994; Montgomery et al., 1998; Dietrich et al., 1995; Guimarães, 2000; Fernandes et al., 2001; Ramos et al., 2001).

Vários autores desenvolveram metodologias para a determinação de área de contribuição
(O'Callaghan e Mark, 1984; Costa Cabral e Burges, 1994), dentre as quais destaca-se a desenvolvida por Quinn et al. (1991), que efetua o cálculo distribuindo o fluxo de forma proporcional entre as células localizadas à jusante, de acordo com a declividade local. Este método obteve melhores resultados para aplicação em áreas de fluxo convergente (Tarboton, 1997).

O presente trabalho tem como objetivo determinar a área de contribuição tanto a partir de uma metodologia que efetua o cálculo direcionando o fluxo para a célula o fluxo de forma proporcional entre as células localizadas à jusante, com a finalidade de se determinar a que apresenta melhor resultado tendo como referência a rede de drenagem.

\section{2. Área de Estudo}

As bacias dos rios Quitite e Papagaio, escolhidas para aplicação das metodologias, localizam-se na vertente oeste do maciço da Tijuca, município do Rio de Janeiro, totalizando uma área de aproximadamente $5 \mathrm{~km}^{2}$ (Figura 1).

No que tange à geologia local, a área é composta por um conjunto diversificado de unidades litológicas, ocorrendo, no entanto, uma predominância do Gnaisse Archer associado a diversos corpos intrusivos (COELHO, 1997; GEORIO, 1996). Geomorfologicamente caracterizase por apresentar um relevo com níveis altimétricos variando de 20 a 950 metros, declividade suave nas porções mais baixas e encostas íngremes naquelas mais elevadas (Guimarães, 2000).

Os solos são bastante rasos nas porções mais elevadas das bacias, havendo um predomínio dos cambissolos e latossolos e tornam-se mais espessos nas porções médias e inferiores em decorrência da diminuição do gradiente.

A área é pouco ocupada e somente nas porções inferiores das bacias verifica-se a intensificação das atividades antrópicas (Fernandes et $a l ., 2001)$. A escolha dessas bacias para a aplicação das metodologias deveu-se ao fato das mesmas se constituírem em áreas de grande instabilidade natural, onde ocorrem inúmeros deslizamentos de terra, sobretudo no período de chuvas intensas e prolongadas.

O cálculo de área de contribuição está diretamente relacionado à confecção de um modelo digital de terreno (MDT). Assim, para que esse cálculo apresente resultados satisfatórios, no que se refere à determinação da área de contribuição, torna-se necessário um modelo confiável e de detalhe. $\mathrm{O}$ 


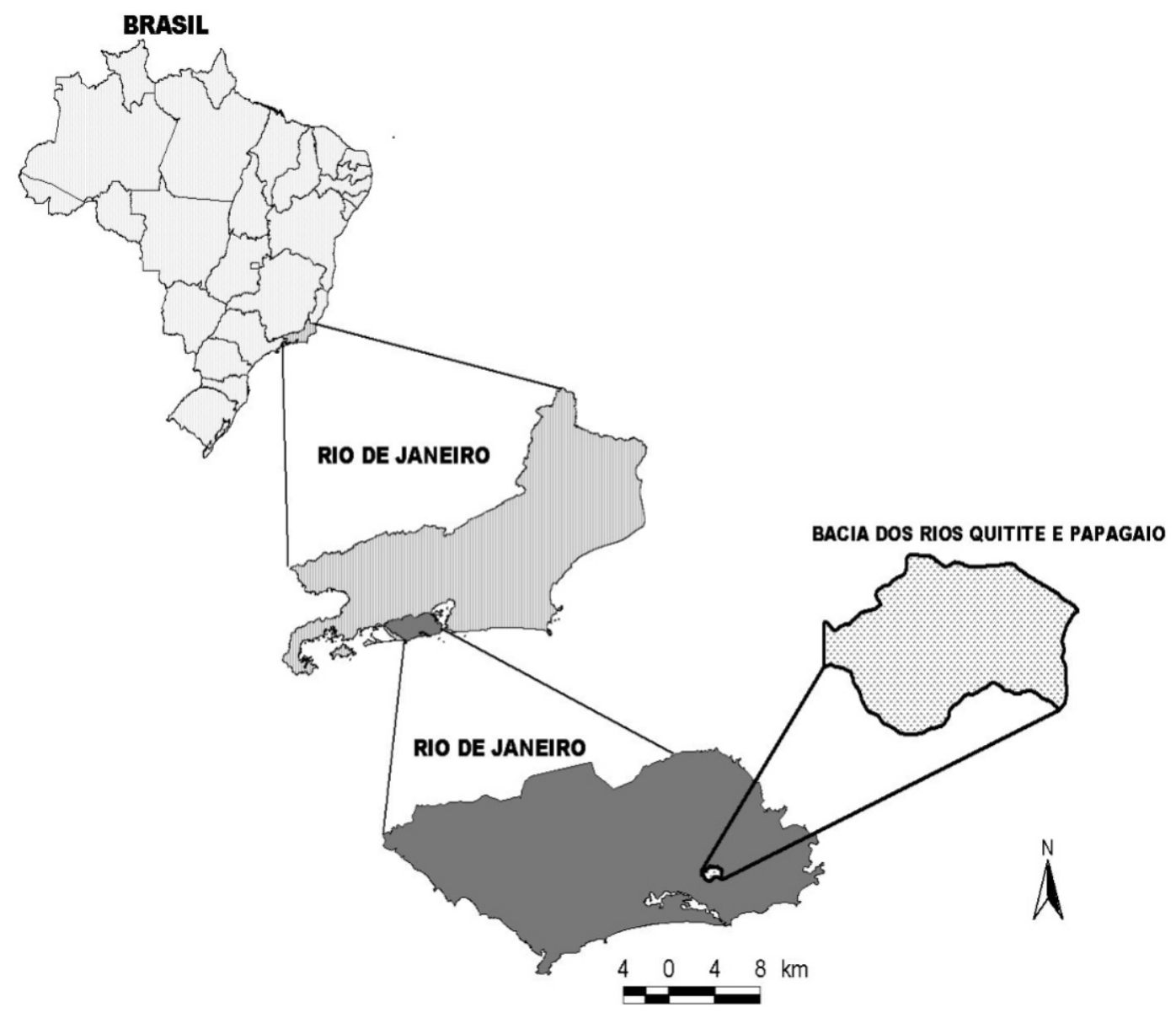

Figura 1 - Localização das bacias dos rios Quitite e Papagaio.

modelo usado nesse trabalho (Figura 2) foi obtido por Guimarães (2000) a partir da restituição de fotografias aéreas, e interpolado pelo módulo Topogrid do software ArcInfo com uma célula de 2 metros de resolução.

\section{Determinação dos Mapas de Área de Contribuição}

A área de contribuição ou área drena da a montante de cada célula de uma matriz está relacionada ao valor da área correspondente à bacia de cada célula específica. A mensuração automatizada de área de contribuição foi realizada, em primeiro lugar, utilizando uma metodologia que direciona o fluxo considerando o declive mais íngreme, que será denominada de Transferência de fluxo para uma única célula (TU) e, em segundo lugar, utilizando uma metodologia que efetua o cálculo distribuindo o fluxo de forma proporcional entre as células localizadas à jusante, aqui denominada de Transferência de fluxo distribuída(TD).

\section{1- Transferência de fluxo para uma única célula - TU}

O cálculo para a distribuição de fluxo e, por conseguinte da área de contribuição, para cada célula da matriz, é estabelecida em função da declividade. $\mathrm{O}$ modelo de direção de declive mais íngreme é um dos mais usados (Milde et al., 1999; Desmet e Govers, 1996; entre outros). Utilizando-se de um Modelo Digital de Terreno com as depressões removidas determinou-se a área de drenagem para cada célula da matriz e, portanto, o mapa de área de contribuição para a área de estudo. 


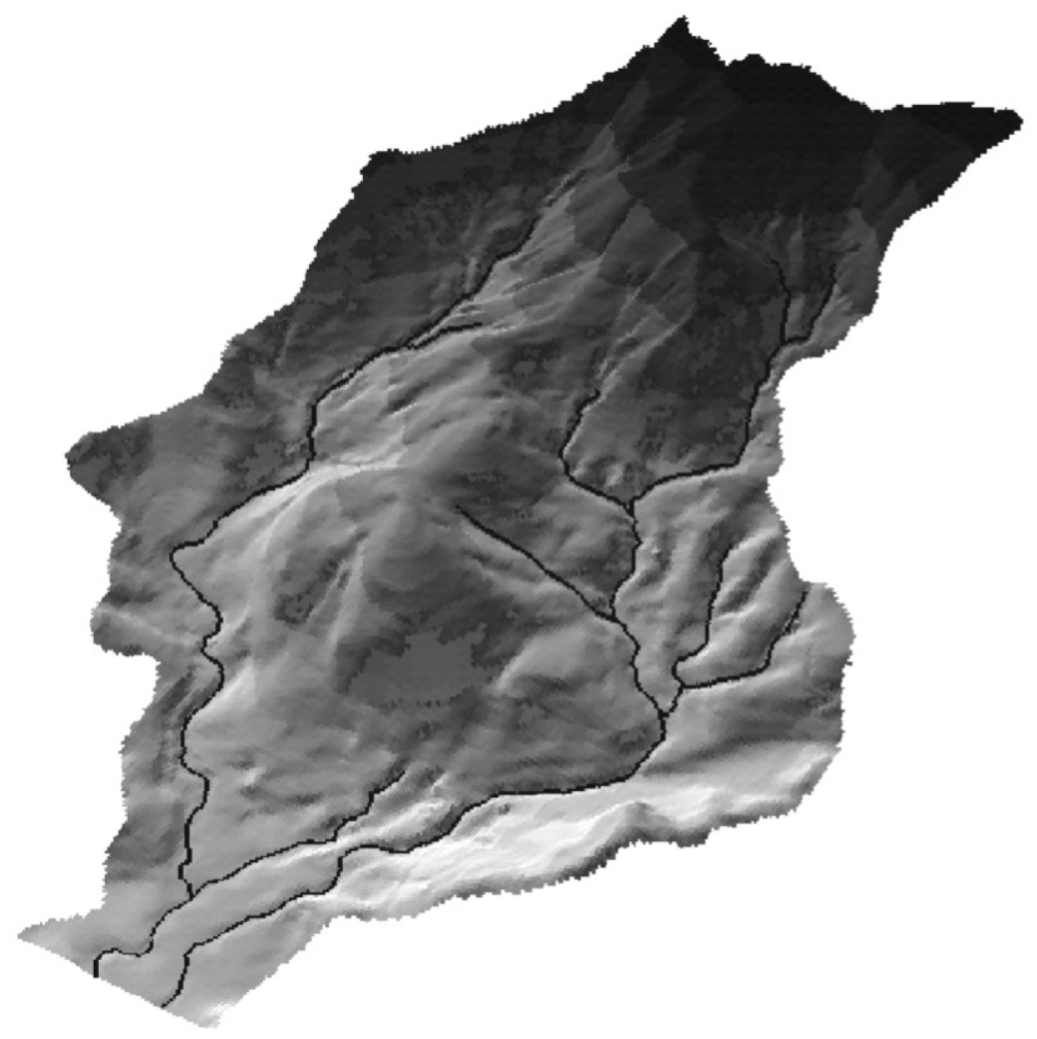

Altimetria $(\mathrm{m})$

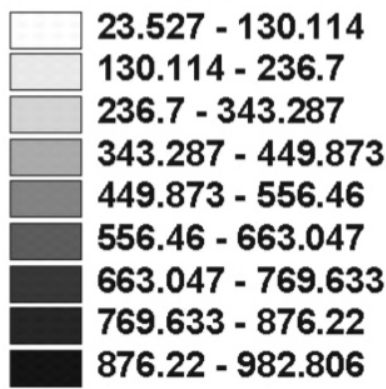

Figura 2 - Modelo Digital de Terreno (MDT) usado para a determinação das áreas de contribuição a partir das metodologias descritas (Fonte: Guimarães, 2000).

Como mostra a Figura 3, para a janela que possui a célula central com o valor 40 , cada célula da matriz é conectada a uma de suas oito células vizinhas segundo a direção de máxima declividade. Ou seja,

\begin{tabular}{|c|c|c|c|}
\hline 63 & 52 & 65 & 47 \\
\hline 49 & 40 & 38 & 35 \\
\hline 54 & 51 & 18 & 27 \\
\hline 57 & 43 & 17 & 12 \\
\hline
\end{tabular}

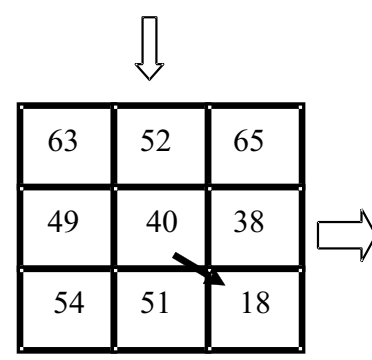

\begin{tabular}{|l|l|l|l|}
\hline 0 & 0 & 0 & 0 \\
\hline 0 & 3 & 1 & 2 \\
\hline 0 & 0 & 9 & 0 \\
\hline 0 & 1 & 2 & 15 \\
\hline
\end{tabular}

Figura 3 - Cálculo da área de contribuição para cada célula da matriz, considerando dentre as oito células vizinhas aquela de direção de declive mais íngreme. considera-se entre as oito células vizinhas aquela de maior declividade para determinar, a partir do escoamento do fluxo, a quantidade de células que drenam uma célula específica. Desta forma, as áreas de contribuição são definidas como o conjunto de todas as células que escoam para uma determinada célula de destino.

\section{2 - Transferência de fluxo distribuída -}

TD

O modelo de direção de declive mais íngreme, como já foi colocado, define a maior declividade entre a célula central e as suas circunvizinhas e direciona todo o fluxo para a célula com maior gradiente. A quantidade de células contribuinte multiplicada pela área de cada célula determina o valor da área de contribuição para aquela célula (Figura 3). No entanto, conforme destacado por Guimarães (2000), essa metodologia provoca erros nos resultados obtidos, decorrentes tanto do volume do fluxo, uma vez que este não escoa completamente para uma única célula (Figura 4), quanto da orientação da matriz com relação à rede de drenagem (Figura 5). 

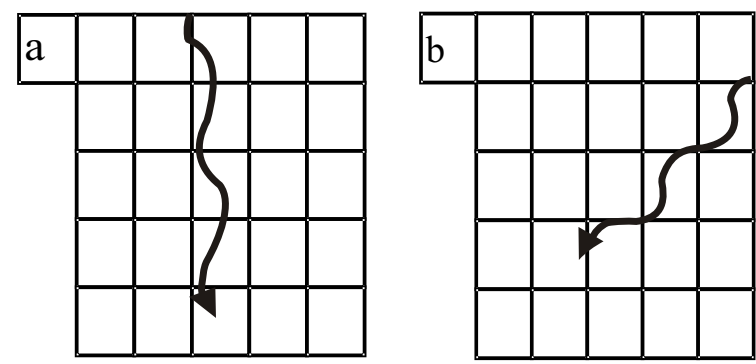

Figura 4 - Representação esquemática mostrando diferentes orientações do fluxo de drenagem em relação à matriz, onde se percebe que no esquema (a) a distribuição de fluxo ocorre em direção à célula a jusante, enquanto que no esquema (b) a direção do fluxo não coincide com a orientação da matriz (Modificado de Guimarães, 2000).

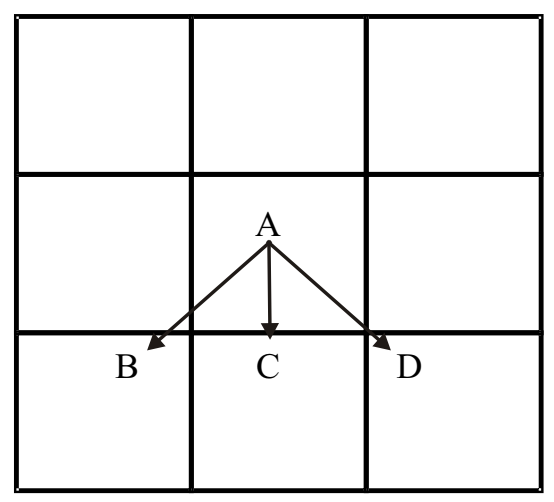

Figura 5 - Representação hipotética de uma matriz, mostrando a distribuição do fluxo proveniente da célula A para as células B, C, D (Modificado de Guimarães, 2000).

Tendo como finalidade a minimização desses erros, Quinn et al. (1991), propuseram uma metodologia para a determinação da área de contribuição em que a fração do fluxo transferida para cada célula à jusante da célula central é proporcional ao produto da distância medida e a um fator de peso geométrico, que depende da direção. Portanto, essa metodologia efetua o cálculo de área de contribuição distribuindo proporcionalmente o fluxo entre as células localizadas à jusante, de acordo com a declividade local, favorecendo, conseqüentemente, a obtenção dos mesmos resultados, independentemente da orientação relativa da topografia em relação à matriz.

Supondo-se que se queira determinar a área de contribuição de uma dada célula A que tem como vizinhas as células $B, C$ e D com altitudes menores e declividades de $0,28,0,32$ e 0,45 , respectivamente (Figura 6). Então, a área de contribuição total da célula $\mathrm{A}$, ou seja, a área drenada à montante será distribuída de forma proporcional para aquelas células respeitando as respectivas declividades. Portanto, a quantidade de fluxo das células B $[0,28 /(0,28+0,32+0,45)], \mathrm{C}[0,32 /(0,28+0,32+0,45)]$ e D $[0,45 /(0,28+0,32+0,45)]$ será multiplicado pelo valor total da área de contribuição da célula $\mathrm{A}$.

Desta forma, a área de contribuição para cada célula da matriz foi determinada, também, a partir dessa metodologia, a fim de comparação com aquela que transfere o fluxo para uma única célula (TU).

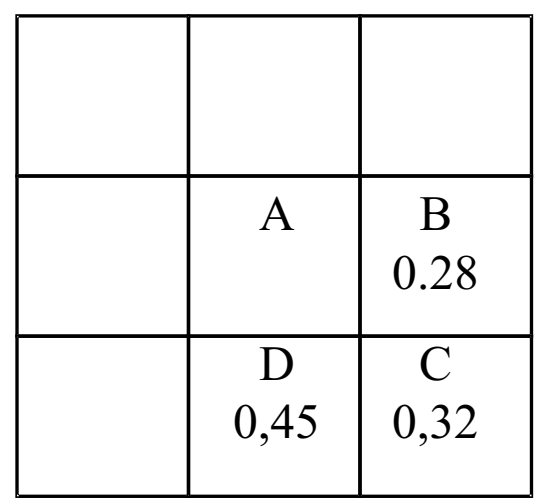

Figura 6 - Representação hipotética de uma matriz em que se observa a declividade das células próxima à célula $\mathrm{A}$ para onde será distribuído o fluxo a montante.

Na metodologia de transferência de fluxo distribuída (TD) determina-se, inicialmente, a proporção da declividade para cada direção. Assim, partindo-se do ponto de menor topografia e acompanhando a direção do divisor de água, calculouse a área de contribuição para aquele ponto. Esse procedimento foi repetido para todas as células da matriz.

\section{Resultados e Discussões}

O mapa de área de contribuição de cada célula da matriz calculado a partir da metodologia TU (Figura 7) apresenta valores que variam de 0 a 84610 $\mathrm{m}^{2}$, e aquele obtido por meio da metodologia TD (Figura 8) de 2 a $1079201 \mathrm{~m}^{2}$.

Aplicou-se um log de 10 em cada mapa para realçar os valores de área de contribuição.

Objetivando uma melhor visualização dos resultados dividiu-se o valor de áreas de contribuição dos mapas obtidos em 9 classes. Comparando esses mapas com o modelo digital de terreno (Figura 2) verifica-se um aumento gradativo da área de 


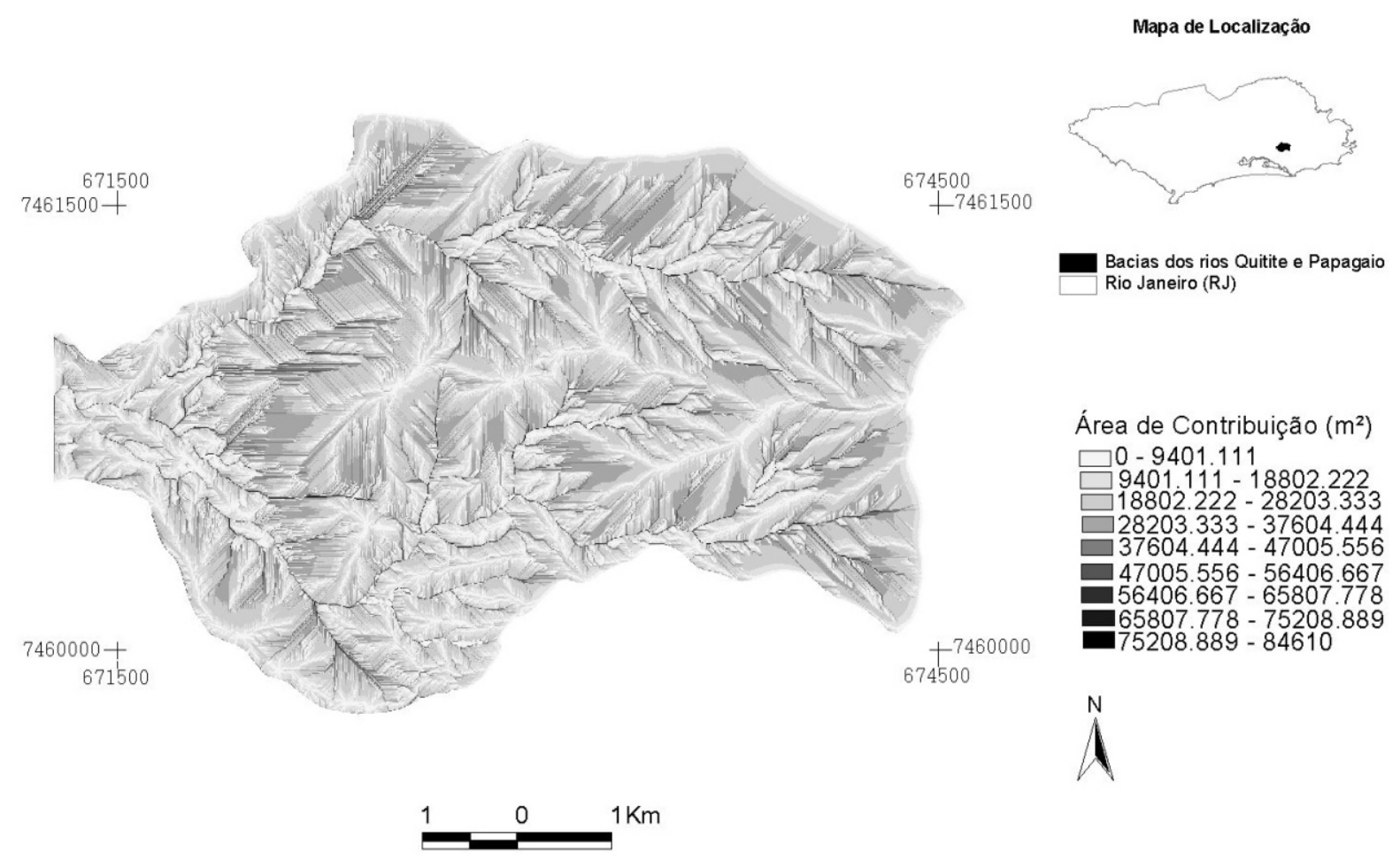

Figura 7 - Área de contribuição calculada a partir da metodologia que transfere o fluxo para uma única célula TU

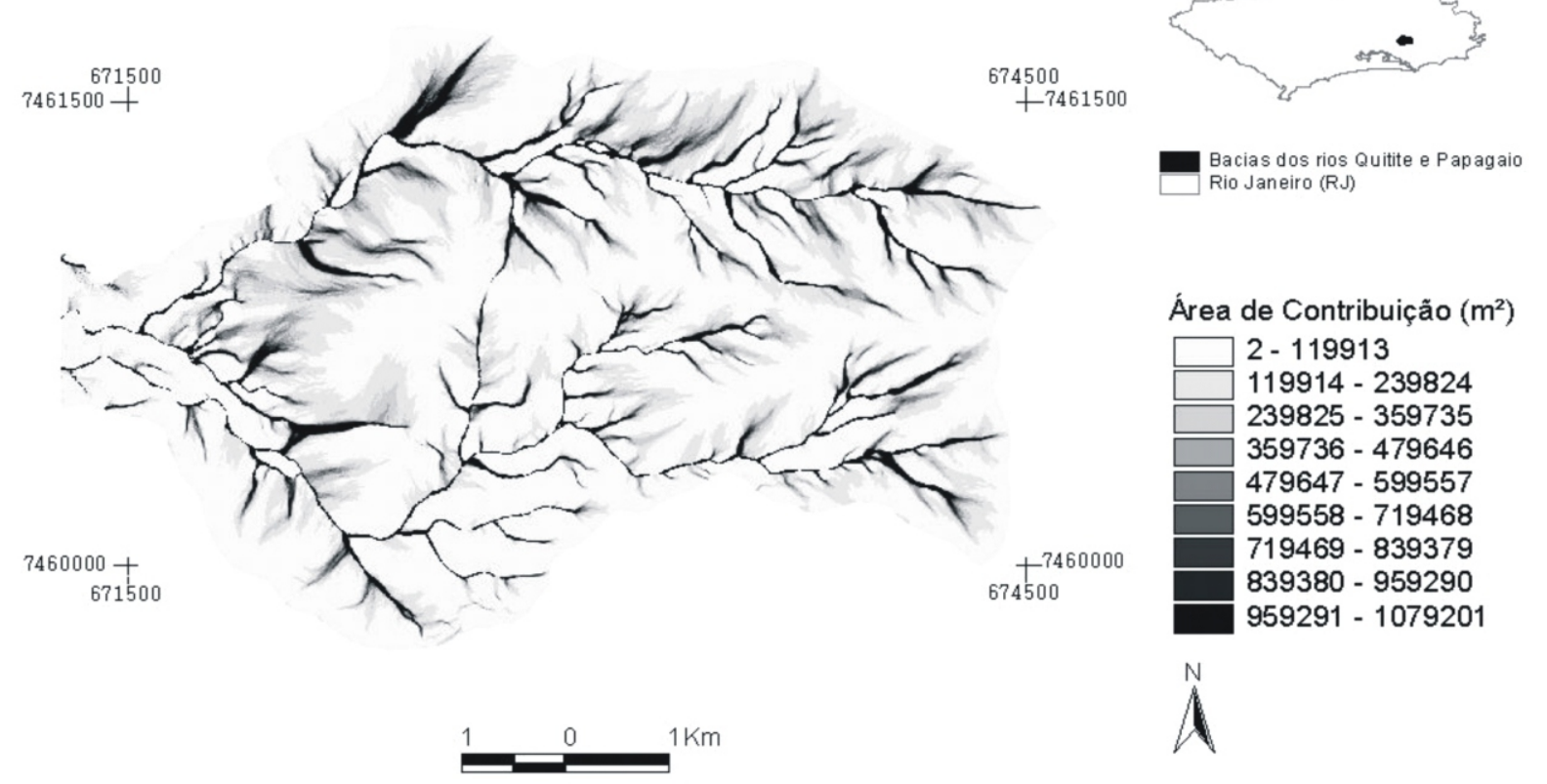

Figura 8 - Área de contribuição obtida a partir da metodologia de transferência de fluxo distribuída - TD 
contribuição em direção às porções do relevo que apresentam os menores índices altimétricos, ou seja, aquelas classes de elevada contribuição localizam-se, como é de se esperar, nas partes mais baixas do relevo, por outro lado, as classes de menor contribuição são observadas nas porções do relevo que apresentam declividades elevadas.

Porém, como mostra a Figura 9, o mapa de área de contribuição determinado por meio da metodologia que transfere o fluxo de forma proporcional entre as células à jusante, de acordo com

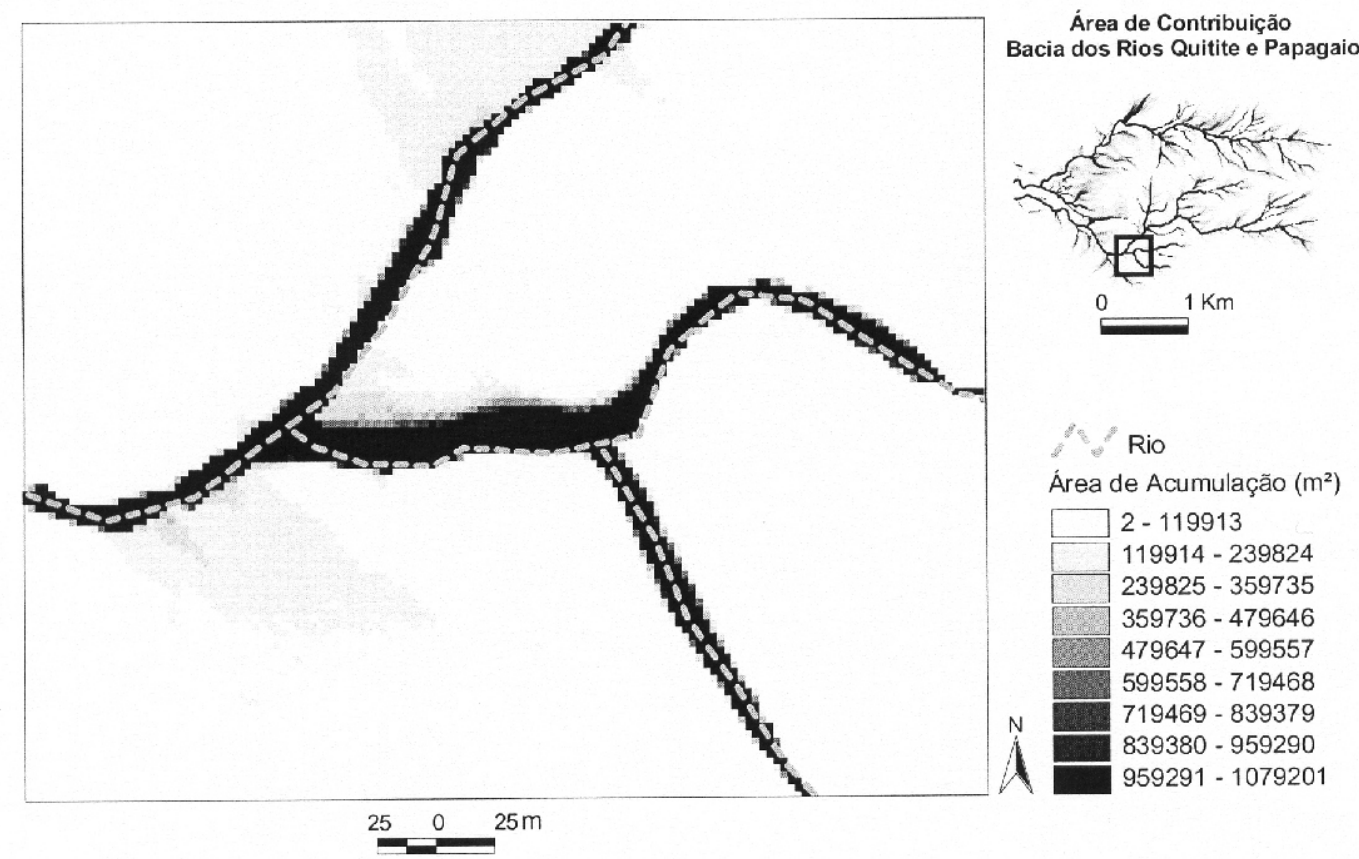

Figura 9 - Zoom do mapa de área de contribuição obtido a partir da metodologia TD

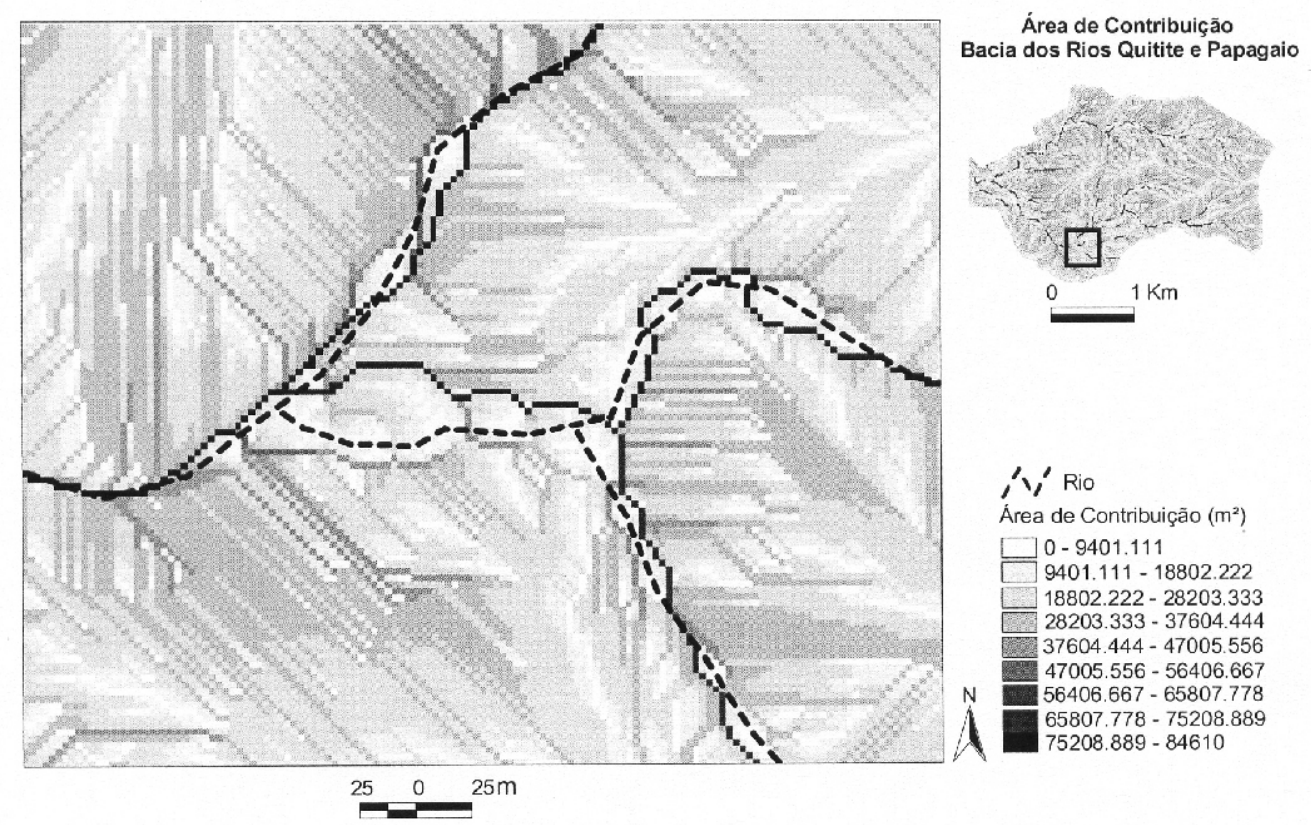

Figura 10 - Zoom do mapa de área de contribuição obtido a partir da metodologia TU 
exatamente na calha, não só da drenagem, mais de todos os caminhos preferenciais do fluxo, além de definir regiões homogêneas de distribuição de fluxo mais coerentes com a natureza.

\section{Conclusão}

O uso de diferentes procedimentos metodológicos pode levar a resultados bastante diferenciados, como observado nesse trabalho. No caso dos mapas de área de contribuição a confiabilidade dos dados está diretamente relacionada à produção de modelos digitais de terreno precisos, assim como à especificação adequada da trajetória do fluxo. Portanto, o resultado de qualquer análise baseado em dados de área de ontribuição será amplamente afetado pela escolha da metodologia.

A metodologia que determina a área de contribuição para cada célula da matriz, em função daquela que apresenta maior valor de declividade, apesar de ser bastante utilizado, produz resultados indesejáveis, como foi visto nesse trabalho. Por outro lado, a metodologia que efetua o cálculo distribuindo proporcionalmente o fluxo entre as células à jusante, uma vez que sugere com exatidão a rede de drenagem, mostra-se mais

eficiente. Portanto, as áreas de contribuição resultantes dessa metodologia podem ser usadas com maior confiabilidade em diversos modelos como: de previsão de áreas de instabilidade, processos erosivos, determinação de zonas de saturação na paisagem, entre muitos outros.

\section{Agradecimentos}

Os autores agradecem a estudante de Geografia da Universidade de Brasília Laiza Rodrigues Leal pela contribuição dada durante a realização desse trabalho e ao Conselho Nacional de Desenvolvimento Científico e Tecnológico (CNPq) pelo apoio financeiro fornecido.

\section{Referências Bibliográficas}

BEVEN, K. J. and KIRKBY, M. J. (1979) Aphysically based, variable contributing area model of basin hydrology. Bulletin of Hydrological Sciences, 24: 43-69.

COELHO, A. L. (1997) Geologia estrutural e hidrogeologia da região do Quitite, Jacarepaguá (RJ): condicionantes dos escorregamentos nas encostas. Monografia de Graduação, Escola de Geologia, UERJ.

COSTA CABRAL, M. e BURGES, S. J. (1994) Digital elevation model networks (DEMON): A model of flow over hillslopes for computation of contibuting and dispersal areas. Water Resour, 30 (6): 1681-1692.

DESMET, P. J. J. e GOVERS, G. (1996) Comparison of routing algorithms for digital elevation models and their implications for predicting ephemeral gullies. Int. J. Geographical Information Systems, 10 (3): 311-331.

DIETRICH, W. E.; W I L SON, C. J.; MONTGOMERY, D. R. e MCKEAN, J. (1993) Analysis of erosion thresholds, channel networks, and landscape morphology using a digital terrain model. Jour. of Geology, 101: 161-180.

DIETRICH, W. E.; REISS, R., HSU, M. L. e MONTGOMERY, D. R. (1995) A processbased model for colluvium soil depth and shallow landsliding using digital elevation data. Hydrological Process, 9: 383-400.

FERNANDES, N. F.; GUIMARÃES, R. F.; GOMES, R. A. T.; VIEIRA, B. C.; MONTGOMERY, D. R.; Greenberg, H. M. (2001) Condicionantes eomorfológicos dos deslizamentos na encostas: Avaliação de metodologias e aplicação de modelos de previsão de áreas susceptíveis. Revista Brasileira de Geomorfologia, 2(1): 51-71.

GEORIO (1996) Estudos geológicos geotécnicos a montante dos condomínios Capim Melado e Vilarejo, Jacarepaguá. Prefeitura do Rio de Janeiro, Relatório Interno.

GUIMARÃES, R. F. (2000) Utilização de um modelo de previsão de áreas susceptíveis à escorregamentos rasos com controle topográfico: Adequação e calibração em duas bacias de drenagem. Tese de Doutorado, Depto de Geografia, UFRJ, 156p.

MILDE, L. C. E.; MORAES, J. M.; FERRAZ, F. F. de B.; MORTATTI, J. e SCHULER, A. E. (1999) Uso do hecprepro no tratamento de modelo digital de terreno em hidrologia: Estudo de caso. Revista Geociências. São Paulo, 18 (2): $285-301$.

MONTGOMERY, D. R. e DIETRICH, W. E. (1994) A physically based model for the topographic control on shallow landsliding. Water Resources Research, 3: 1153-1171.

MONTGOMERY, D. R.; SULLIVAN, K. e GREENBERG, H. M. (1998) Regional test of a model for shallow landslides. Hydrological Processes, 12: 943-955.

O'CALLAGHAN, J. F. and MARK, D. M. (1984) The extraction of drainage network from digital elevation data. Comput Vision Graphics Image Process, 28: 328-344.

O'LOUGHLIN, E. M. (1986) Prediction of surface saturation zones in natural catchments by topographic analysis. Water Resources 
Research, 22 (5): 794-804.

QUINN, P.; BEVEN, K.; CHEVALLIER, P. and PLANCHON, O. (1993) The prediction of hillslope flow paths for distributed hydrological modelling using digital terrain models. In: BEVEN, K. J. and MOORE, I.D. (ed.) Terrain analysis and distributed modelling in hydrology. John Wiley \& Sons, Chichester, England: 63-84.

RAMOS, V. M.; GUIMARÃES, R. F.; REDIVO, A. L.; GOMES, R. A. T.; FERANADES, N. F.; CARVALHO JUNIOR, O. A. de. (2001) Estudo de movimentos de massa com aplicação de um modelo de previsão de áreas susceptíveis a escorregamentos. Anais do IX Simpósio Brasileiro de Geografia Física Aplicada. Recife: 72-73.

RENNÓ, C. D. e SOARES, J. V. (2000) Modelos hidrológicos para gestão ambiental. Instituto
Nacional de Pesquisas Espaciais (INPE) Programa de Ciência e Tecnologia para a Gestão de Ecossistemas. Ação "Métodos, modelos e geoinformação para a gestão ambiental”. Relatório Técnico Parcial. São Paulo, 60p.

TARBOTAN, D. G. (1997) A new method for the determination of flow directions and upslope areas in grid digital elevation models. Water Resources Research, 33 (2): 309-319. 